\title{
EFFECT OF PROSTAGLANDINS ON THE DEVELOPMENT OF RABBIT EMBRYOS
}

\author{
C. H. SPILMAN \\ Fertility Research, The Upjohn Company, Kalamazoo, Michigan, 49001, U.S.A.
}

(Received 4th February 1974)

The mammalian oviduct provides the environment for the embryo during its early development. Since oviducal fluid is composed of secretory products and products of transudation (Hamner, 1971), systemically administered compounds might influence the oviducal environment in two ways: (1) by altering the volume and/or chemical composition, and (2) by entering the oviducal fluid directly. The following experiment was performed to evaluate the influence of prostaglandins on embryo development.

Twenty-two New Zealand does were injected intramuscularly with 150 i.u. PMSG (Ayerst Laboratories, Inc.) $72 \mathrm{hr}$ before being mated naturally or artificially inseminated. Immediately after insemination, all does were injected intravenously with 100 i.u. HCG (Sigma Chemical Co.) and, 6 to $7 \mathrm{hr}$ later, both oviducts were ligated with silk sutures at the uterotubal junction. Because of the reported effects of prostaglandins on egg transport (Ellinger \& Kirton, 1972; Chang, Hunt \& Polge, 1973), it was thought that this ligation was necessary to ensure subsequent recovery of embryos from the oviducts. Females were injected subcutaneously with phosphate buffer vehicle $(0 \cdot 2 \mathrm{M}, \mathrm{pH} 7 \cdot 3)$, $\mathrm{PGE}_{1}, \mathrm{PGE}_{2}$ or $\mathrm{PGF}_{2 \alpha}$ at 12 and $24 \mathrm{hr}$ after HCG. Prostaglandins were administered in doses of $3 \mathrm{mg} / \mathrm{kg}$ body weight.

Two- and four-cell embryos were flushed from the oviducts 30 to $32 \mathrm{hr}$ after HCG. The flushing and culture media and embryo culture system were those described by Kane \& Foote (1970). After 90 to $96 \mathrm{hr}$ in culture, embryos were classified and scored according to their stage of development. The following scoring system was used: 1 = cleaving but less than a morula, $2=$ morula (sixteencell stage), $3=$ early blastocyst (blastocoele just visible), $4=$ blastocyst (blastocoele at least half the size of the embryo), $5=$ expanding blastocyst (zona pellucida attenuated), $6=$ hatching blastocyst (zona pellucida ruptured). Each individual culture usually contained ten embryos making the maximum possible score per culture equal to sixty. Cultures containing less or more than ten embryos were corrected to the base 10 . A total of 386 embryos was cultured. Statistical differences of mean embryo development were calculated by analysis of variance (Snedecor \& Cochran, 1969).

The mean scores for control, $\mathrm{PGE}_{1}, \mathrm{PGE}_{2}$ and $\mathrm{PGF}_{2 \alpha}$ groups were, respectively, $48 \cdot 9 \pm 1 \cdot 8,43 \cdot 7 \pm 5 \cdot 8,37.5 \pm 3 \cdot 8$ and $41.9 \pm 3.0$ (mean \pm S.E.). Only the score for embryos collected from females treated with $\mathrm{PGE}_{2}$ was significantly $(P<0.03)$ different from that of controls. The average developmental stage attained in vitro for control embryos was an expanding blastocyst. For 
both $\mathrm{PGE}_{1}$ and $\mathrm{PGF}_{2 \alpha}$ treatments, it was the blastocyst stage. By contrast, embryos from animals treated with $\mathrm{PGE}_{2}$ developed, on average, to the early blastocyst stage; many had granular appearing blastomeres and were often distorted. These characteristics were not frequently observed in other treatment groups.

Further indication of the inhibitory effects of $\mathrm{PGE}_{2}$ is evident in the distribution of developmental stages attained in vitro (Table 1). In control cultures, there was an increasing distribution of developmental stages with a total of $52.4 \%$ reaching the hatching blastocyst stage. After $\mathrm{PGE}_{1}$ or $\mathrm{PGF}_{2 \alpha}$ treatment, more

Table 1. Distribution of rabbit embryo developmental stages attained in vitro after prostaglandin treatment in vivo

\begin{tabular}{|c|c|c|c|c|c|c|}
\hline \multirow{2}{*}{ Treatment } & \multicolumn{6}{|c|}{ Developmental stage* } \\
\hline & 1 & 2 & 3 & 4 & 5 & 6 \\
\hline $\begin{array}{l}\text { Control (193) } \\
\text { PGE }_{1}(41) \\
\text { PGE }_{2} \text { (58) } \\
\text { PGF }_{22} \text { (94) }\end{array}$ & $\begin{array}{l}0.5 \\
0 \\
1 \cdot 8 \\
3 \cdot 2\end{array}$ & $\begin{array}{r}5 \cdot 7 \\
17 \cdot 1 \\
13 \cdot 8 \\
16 \cdot 0\end{array}$ & $\begin{array}{r}9 \cdot 3 \\
17 \cdot 1 \\
31 \cdot 0 \\
12 \cdot 8\end{array}$ & $\begin{array}{l}15 \cdot 0 \\
19 \cdot 4 \\
15 \cdot 5 \\
13 \cdot 8\end{array}$ & $\begin{array}{r}17 \cdot 1 \\
9 \cdot 8 \\
31 \cdot 0 \\
24 \cdot 4\end{array}$ & $\begin{array}{r}52 \cdot 4 \\
36 \cdot 6 \\
6 \cdot 9 \\
29 \cdot 8\end{array}$ \\
\hline
\end{tabular}

The numbers of embryos cultured are given in parentheses.

The tabular values represent the percentage of the total number of cultured embryos which reached Stages 1 through 6 of development.

* See text for explanation of developmental stages.

embryos developed to the hatching blastocyst stage than to earlier stages; however, there was a fairly even distribution of morulae, early blastocysts, blastocysts and expanding blastocysts. Following PGE $_{2}$ treatment, only $6.9 \%$ of cultured embryos developed to the hatching stage, and $31 \%$ did not develop beyond the early blastocyst stage. An additional $31 \%$ of the embryos in the $\mathrm{PGE}_{2}$-treatment group developed to the expanding blastocyst stage.

To define the stage of embryo development at which the effect of treatment with $\mathrm{PGE}_{2}$ was manifested, an additional analysis was performed. The proportion of embryos progressing from each stage of development to the next was

Table 2. Proportion of cultured rabbit embryos that reached each stage of development and progressed to the subsequent stage

\begin{tabular}{|c|c|c|c|c|c|}
\hline \multirow{2}{*}{ Treatment } & \multicolumn{5}{|c|}{ Developmental stage $\dagger$} \\
\hline & $1 \rightarrow 2$ & $2 \rightarrow 3$ & $3 \rightarrow 4$ & $4 \rightarrow 5$ & $5 \rightarrow 6$ \\
\hline $\begin{array}{l}\text { Control } \\
\text { PGE }_{1} \\
\text { PGE }_{2} \\
\text { PGF }_{2 \alpha}\end{array}$ & $\begin{array}{l}0.99 \pm 0.01 \\
1.0 \pm 0 \\
0.98 \pm 0.02 \\
0.97 \pm 0.02\end{array}$ & $\begin{array}{l}0.94 \pm 0.03 \\
0.84 \pm 0.06 \\
0.84 \pm 0.06 \\
0.85 \pm 0.06\end{array}$ & $\begin{array}{l}0.92 \pm 0.02 \\
0.78 \pm 0.07 \\
0.64 \pm 0.16 \\
0.86 \pm 0.07\end{array}$ & $\begin{array}{l}0.81 \pm 0.06 \\
0.67 \pm 0.20 \\
0.55 \pm 0.19 * \\
0.77 \pm 0.08\end{array}$ & $\begin{array}{l}0.64 \pm 0.07 \\
0.60 \pm 0.24 \\
0.10 \pm 0.07 * \\
0.59 \pm 0.06\end{array}$ \\
\hline
\end{tabular}

The tabular values are mean proportions \pm standard error.

† See text for explanation of developmental stages.

* Significantly $(P<0.01)$ smaller than control. 
compared using the Wilcoxon test (Snedecor \& Cochran, 1969). These proportions are presented in Table 2. Treatment with $\mathrm{PGE}_{1}$ and $\mathrm{PGF}_{2 \alpha}$ caused no significant effects when compared with the control cultures, but the effect of $\mathrm{PGE}_{2}$ was first evident when blastocyst expansion should be occurring. Of those embryos reaching the blastocyst stage, a significantly $(P<0.01)$ smaller proportion progressed to the expanding blastocyst stage than in control cultures. Of those embryos that did expand, significantly $(P<0.01)$ fewer continued to the hatching blastocyst stage in $\mathrm{PGE}_{2}$ cultures.

Inhibition of embryo development in vitro following $\mathrm{PGE}_{2}$ treatment in vivo during the time of fertilization and the first two cleavage divisions indicates an effect by several possible mechanisms. The viability of spermatozoa may have been altered so that although normal fertilization occurred subsequent embryo development was inhibited. A similar effect has been reported to occur when rabbit spermatozoa are subjected to heat-stress before insemination (Ulberg \& Burfening, 1967). A second mode of action may be alteration of the normal oviducal milieu to one which was detrimental to the early embryo. Since oviducal fluid is partly composed of transudate, it is also possible that $\mathrm{PGE}_{2}$ entered the luminal fluids and had a direct effect on the early embryo. In view of the reported effects of E-series prostaglandins on gastric secretion (Robert, 1967), a likely explanation at the present time is that $\mathrm{PGE}_{2}$ caused an alteration in oviducal fluid volume and/or composition. Since the effect of $\mathrm{PGE}_{2}$ treatment was first evident when blastocyst expansion should occur, it is possible that the zona pellucida was altered in some manner which did not permit its attenuation. Labhsetwar (1973) reported that $\mathrm{PGE}_{1}$ and $\mathrm{PGE}_{2}$ caused a delay in the development of rat embryos, but that $\mathrm{PGF}_{2 \alpha}$ had no effect.

The assistance of $\mathrm{Dr} \mathrm{M}$. A. Johnson and Mr J. F. Norland is gratefully acknowledged.

\section{REFERENCES}

Chang, M. C., Hunt, D. M. \& Polge, C. (1973) Effects of prostaglandins (PGs) on sperm and egg transport in the rabbit. Adv. Biosci. 9, 805.

EILINGER, J. V. \& KIRTON, K. T. (1972) Ovum transport in rabbits injected with prostaglandin $\mathrm{E}_{1}$ or $\mathrm{F}_{2_{\alpha}}$. Biol. Reprod. 7, 106.

Hamner, C. E. (1971) The oviduct fluid. In Pathways to Conception, p. 30. Ed. A. I. Sherman. C. C. Thomas, Springfield, Illinois.

KANE, M. T. \& FOOTE, R. H. (1970) Culture of two- and four-cell rabbit embryos to the expanding blastocyst stage in synthetic media. Proc. Soc. exp. Biol. Med. 133, 921.

LABHSETWAR, A. P. (1973) Effects of prostaglandins $E_{1}, E_{2}$ and $F_{2 \alpha}$ on zygote transport in rats : induction of delayed implantation. Prostaglandins, 4, 115.

Rosert, A. (1967) Antisecretory property of prostaglandins. In Prostaglandin Symposium of the Worcester Foundation for Experimental Biology, p. 47. Eds. P. W. Ramwell and J. E. Shaw. Interscience Publishers of John Wiley \& Sons, New York.

SNedecor, G. W. \& Cochran, W. G. (1969) Statistical Methods, 6th edn, pp. 130 and 258. Iowa State University Press, Ames.

Ulberg, L. G. \& Burfening, P. J. (1967) Embryo death resulting from adverse environment on spermatozoa or ova. F. Anim. Sci. 26, 571. 